\title{
Colopexia como tratamento de prolapso retal em ovino - relato de caso
}

Cláudia Medeiros Rodrigues ${ }^{[a]}$, Claudia Acosta Duarte ${ }^{[b]}$, Elizabeth Schwegler[ ${ }^{[c]}$, Ricardo Pozzobon ${ }^{[d]}$, Inácio Manassi da Conceição Brandolt ${ }^{[e]}$, Geórgia Camargo Góss ${ }^{[f]}$, Rosana Klaus ${ }^{[b]}$, Gustavo Klaus ${ }^{[b]}$

\footnotetext{
[a] Programa de Pós-graduação em Medicina Veterinária, Universidade Federal de Santa Maria (UFSM), Santa Maria, RS, Brasil

[b] Universidade Federal do Pampa (UNIPAMPA), Uruguaiana, RS, Brasil

${ }^{[c]}$ Instituto Federal Catarinense (IFC), Araquari, SC, Brasil

[d] Universidade Federal de Santa Maria (UFSM), Santa Maria, RS, Brasil

${ }^{[e]}$ Hospital Universitário Veterinário, Universidade Federal do Pampa (UNIPAMPA), Uruguaiana, RS, Brasil

[f] Programa de Residência Integrada em Medicina Veterinária, Universidade Federal do Pampa (UNIPAMPA), Uruguaiana, RS, Brasil
}

*Autor correspondente

e-mail: claudiamedeirosrodrigues@gmail.com

\section{Resumo}

O prolapso retal é uma afecção bastante comum em ovinos de cauda curta, o qual consiste na protusão da mucosa retal através do ânus, podendo apresentar-se de maneira parcial ou completa variando de acordo com as estruturas envolvidas. 0 objetivo do presente relato é descrever o tratamento de prolapso retal instituído em um ovino por meio de colopexia. Foi atendido no setor de Clínica e Cirurgia de Grandes Animais do Hospital Universitário Veterinário da Universidade Federal do Pampa, uma ovelha da raça Merino Australiano, de 4 anos e $31 \mathrm{~kg}$, que apresentava o quadro de prolapso retal. Na anamnese, constatou-se que os sinais clínicos já existiam há dois meses e foi citada a piora do quadro. À inspeção e palpação, notou-se que havia presença de miíase na região perineal e ausência de esfíncter anal. Ao exame físico não foram observadas alterações. Instituiu-se tratamento com flunixin meglumine e enrofloxacina, retirada das larvas e limpeza da região anal. Optou-se, então, pela realização da colopexia, procedimento cirúrgico que, após colocação das vísceras em posição anatômica, permite fixar o cólon na parede abdominal. Neste caso, realizou-se, após laparotomia mediana pré-púbica, escarificação da parede abdominal e do cólon descendente. A fixação dessas estruturas foi realizada com padrão de sutura contínua simples, com fio poliglactina 2-0. No período pós-operatório, instituiu-se a mesma terapia medicamentosa do pré-operatório, além da limpeza da ferida cirúrgica. Mesmo que recidivas sejam comuns, após 10 dias não foi observado novo prolapso retal, sendo esta uma técnica 
eficiente para resolução da afecção em pequenos ruminantes e nos casos em que o esfíncter anal esteja ausente. Porém, é uma técnica relativamente complexa e normalmente utilizada em casos recidivantes e/ou em animais de alto valor econômico. 